Article

\title{
An Approach Incorporating User Preferences in the Design of Sanitation Systems and Its Application in the Rural Communities of Chiapas, Mexico
}

\author{
Thalía Turrén-Cruz $^{1, *(\mathbb{C} \text {, Juan Alejandro García-Rodríguez }}{ }^{2}$, , Rodrigo E. Peimbert-García $^{1,3}$ \\ and Miguel Ángel López Zavala ${ }^{1, *(1)}$ \\ 1 Water Center for Latin America and the Caribbean, School of Engineering and Sciences, \\ Tecnologico de Monterrey, Monterrey 64849, Mexico; Rodrigo.peimbert@tec.mx \\ 2 Department of Political Science and International Relations, Tecnologico de Monterrey, \\ Monterrey 64849, Mexico; juanagr74@gmail.com \\ 3 School of Engineering, Macquarie University, New South Wales 2113, Australia \\ * Correspondence: thalia_turren@hotmail.com (T.T.-C.); Miganloza@tec.mx (M.Á.L.Z.)
}

Received: 7 November 2019; Accepted: 7 January 2020; Published: 31 January 2020

check for updates

\begin{abstract}
Globally, the numerous efforts exerted toward providing basic sanitation services to people have not been sufficient to achieve universal coverage. In developing countries worldwide, many policies, strategies, initiatives, and projects on basic sanitation have failed, despite important investments. Of the several reasons explaining the failure, it is remarkable to note that such approaches have focused mainly on improving the technology of the sanitation system without considering the human aspects, such as user preferences. Moreover, there is currently no comprehensive approach that ensures the provision of a sanitation service that users want or need to satisfy their needs. In this regard, this study proposed an approach to identify the variables and indicators that represent user preferences in the selection and creation of more holistic sanitation strategies, technologies, systems, and services. The proposed approach was applied in rural communities of Chiapas, the poorest state of Mexico, and was effective in identifying user preferences, which suggests that it could be an intrinsic part of the design, planning, and implementation process toward leading rural communities to achieve sustainable development goals on universal basic sanitation. The evaluation results also demonstrated that among the preferences linked to the technical features, esthetics, costs of the system, and socioeconomic-related aspects were the most important to be considered in the provision of basic sanitation. The study points out the necessity of understanding how culture, preferences, practices, and socioeconomic conditions directly affect the possibilities for users to gain access to basic sustainable sanitation services.
\end{abstract}

Keywords: rural sanitation; basic sanitation; user preferences; sustainable development goals

\section{Introduction}

In 1992, the World Health Organization (WHO) published a book titled "A Guide to the Development of On-Site Sanitation," highlighting the need for access to basic sanitation, such as the safe disposal of excreta, which is fundamentally important for the health and welfare of the community, including the control of its water supplies, vectors of disease, and housing conditions, among others. The publication also stressed that sanitation is of primary significance in human health as long as the lack of full sanitation services coverage represents a major problem for the integral development of human beings [1,2]. However, since this publication, the need for basic sanitation was one of the issues tackled in the United Nation's Millennium Development Goals (MDGs) in 2005 and Sustainable Development Goals (SDGs) in 2015, which, in some cases, have been predicted to worsen as a result of 
the rapid population growth and being less considered for improvement and financial investment as compared to drinking water services $[1,3,4]$.

Across the globe, many people, especially those living in the most precarious socioeconomic situations in the peri-urban and rural areas, do not have access to sanitation [5,6]. Moreover, almost 1000 children die every day from diseases caused by poor water and sanitation conditions, which should be preventable. It is estimated that 2.4 billion people do not even have basic sanitation. In addition, approximately $80 \%$ of wastewater is discharged into water bodies without proper treatment [7]. Many of these serious conditions have been encouraged by bad sanitation policies and projects, mainly because of government approaches that are not suited to the preferences of the users [8], which result in the failure of the strategies implemented, or because of the use of conventional, old, and outdated technologies [9-11]. High-ranking officials and decision-makers oftentimes do not include the users when selecting the technology or when implementing it in the sanitation system $[9,11]$.

Worse, these approaches do less in preventing or improving the situation as they do not represent what users really need or prefer in the sanitation system [12]. Thus, it is important for decision-makers to understand people's culture and behavior, and to integrate the users in the formulation of strategies for implementation $[13,14]$. Practically, the sanitation systems must also be designed to be feasible, affordable, and user-friendly $[5,6,8]$. In this regard, the identification of the users' needs and preferences seems to be a central issue based on several authors' reports showcasing the fact that the desired interventions were not holistic and did not meet user needs, and thus, could not be performed correctly $[6,8,10,13,15-18]$. In fact, a considerable number of research studies found several factors and indicators that seemed to correlate the choice of the best sanitation system with respect to certain users. These methods and compendium of indicators vary and require different types of approaches. Nevertheless, all the above authors had a common conclusion stating that a sanitation system should be developed with an approach that is user-centered, cannot generalize results, must link the user needs with resources found locally, must embrace a sociocultural approach, and must not be top-down $[6,8,10,13,15-18]$.

Meanwhile, countries like Mexico aim to overcome the precarious conditions brought about by issues in water and sanitation and to achieve universal coverage of such services. In 2012, the Mexican government reformed the fourth article of its constitution to incorporate its citizens' human rights to water and sanitation [19], which infers a lot about its political legislators having understood the need to address the water crisis and sanitation precariousness in the locale [20]. Although the 2018 National Water Commission of Mexico (CONAGUA) report stated that in 2015 about $92.8 \%$ of the population had access to sewerage and basic sanitation services and that the national coverage of public sewerage and septic tanks was $91.4 \%$, these data referred mainly to the sewerage coverage, but not to wastewater collection and treatment (sanitation) [21].

The End of Mission Statement of the Special Rapporteur on the Human Rights to Water and Sanitation in México (2017) described that a large portion of the country's population has access to very low-quality water and sanitation services or do not have both services at all [22]. OXFAM, Oxford's Committee for Famine Relief, also published a report depicting the strong likelihood of deficient water services with poverty, as portrayed in the inequality gap in Mexico where the lower-income citizens have to pay more but receive lower-quality services than the high-income users [23]. Such a situation is said to be more complicated in the southern states of Mexico, where the poverty levels are four times higher than the national average and risk factors, such as undernourishment, polluted water sources, poor sanitation services, and air pollution, are likely to increase child mortality by eight times more than in northern Mexico [24,25].

The economy of Chiapas, the country's poorest state, depends on primary exports like unroasted coffee, bananas, and raw sugar, which make it a state with no economic diversification [26,27]. About $70 \%$ of its $5,217,908$ inhabitants do not have access to drinking water and sanitation, whereas approximately only $26 \%$ of the homes were installed with piped water [28-30]. Thus, the region has a high economic privatization index, a high vulnerability to climate phenomena, and one of the biggest 
indigenous populations in the country $[28,29]$ that are most affected by the inequality in the provision of water and sanitation services [11,23]. Additionally, all water streams in the area are polluted as most of the wastewater running throughout the region remains untreated [30,31].

Considering the scenarios above, it is imperative for policymakers, decision-makers, researchers, and technical sanitation professionals to be equipped with an instrument that allows the identification of indicators to determine user preferences as input for the selection and creation of sanitation systems, and thus, ensure improvement in the quality of life of the users as well as in the utilization of the systems for implementation. It is essential that the solutions be developed parallel to the context and environment of the locality, should be affordable to users and can be used correctly and consistently to improve health [32].

This study has a two-fold objective. First, it aims to develop an approach to identify the variables and indicators that allow the determination of user preferences required in the selection and implementation of more holistic sanitation strategies, technologies, systems, and services. Second, it aims to apply such an approach in the rural communities of the state of Chiapas in Mexico to determine the user preferences needed for the selection of appropriate sanitation systems. The effectiveness of the proposed approach in identifying the user preferences is discussed herein, which makes it feasible as an intrinsic part of the design, planning, and implementation process in leading rural communities toward achieving sustainability and SDGs on universal basic sanitation.

\section{Methodology}

\subsection{Preparation of the Approach to Identify the Variables and Indicators}

An exhaustive literature review of specialized academic and scientific websites (Scopus, Web of Science, Google Scholar, Wiley Journals, Scielo, among others) was conducted to identify the required social variables and indicators to determine user preferences as input for the selection and implementation of more holistic sanitation strategies, technologies, systems, and services. The social variables were prepared by grouping them in a matrix with respect to:

i) the recurrence of these variables across different studies (saturation);

ii) the influence of these variables;

iii) and, their importance in describing and identifying the needs and desires of the users.

To simplify the data analyses, the indicators were defined based on the variables selected.

As soon as the variables and indicators were identified, a field survey protocol was prepared in three sections, as follows:

Section a of the survey was structured for the collection of the socioeconomic information of the users, including their age, gender, school level, occupation, number of family members, access to basic sanitation, type of sanitation service, willingness to change the actual systems, weekly income, capacity of investment, and community location;

Section $b$ evaluates the importance of sanitation with respect to other services such as piped or potable water, electricity, sewerage, mobile phone, internet, and television; and

Section c gathers information related to the users' preferences and is divided into 10 subsections that correspond to the rest of the indicators: technical, ease, cost, esthetics, surroundings, user, peer influence, hygiene, social interactions, and environment.

\subsection{Application of the Approach in Rural Localities of Chiapas}

A field survey was conducted in the rural communities of Pijijiapan, state of Chiapas, Mexico, targeted to users and decision-makers 18 years and older. The survey for the users was different from that for the decision-makers, where the aim was to understand the differences and the values each group contributes to the sanitation service. The municipality was chosen because of its level of poverty and illiteracy. For the survey, sample size was estimated based on the total number of communities 
(788) in the municipality using the protocol described in [33]. Subsequently, the Pareto principle was employed as it was deemed suitable to represent the largest section of the population. Communities with more than 100 inhabitants and representing $80 \%$ of the population were grouped, and then a new sample size was calculated to set the number of interviews to be applied. The information was collected by means of mobile phones and an app named EpiCollect+ that allows data storage on the cloud.

Respondents (users) were selected by means of a snowball-type sampling [34], whereas decision-makers were authorities or leaders of the communities. The data collected were analyzed and processed using Pearson's chi-square tests for associations, given a significance level of $\alpha=5 \%$. Relationships between the indicators were analyzed and described to identify user preferences. Two-proportion and Pearson's chi-square tests were also conducted for some specific users and decision-makers' answers to identify any similarities or differences in their responses and to disclose if authorities are aware of the users' interests in and needs of sanitation. Issues selected for the comparison included the preference between sanitation and other services, willingness to change, location, management, privacy, and construction material.

\section{Results}

\subsection{Preparation of the Approach to Identify the Variables and Indicators}

Most of the studies reviewed focused on one or two aspects of sanitation, such as usage or ownership and cost or technical features, whereas some had a significant number of variables. Here, all the aspects were gathered into indicators for ease of analysis and to cover as many aspects of sanitation as possible to be represented in a more holistic approach that identifies the important social variables and indicators required to determine user preferences, as shown in Table 1.

Every indicator was used to evaluate specific constituents. For instance, cost was used to assess the economic capacity or willingness of the user to pay to build (or improve) and maintain the system, esthetics, to evaluate the space available to build or improve the system and its appearance, as indicated by the floor type and color preferences, ease, to assess the frequency of use and periodicity of maintenance to keep the correct function of the system, hygiene, to indicate the periodicity of cleaning the system and handwashing of the user, peer influence, to assess the customs and will for change and determine if there is community pressure on the kind of system used, surroundings, to evaluate concerns regarding climatic conditions in the area, user, where and how the user prefers or uses the system, technical, to assess the willingness of the user to manipulate wastes for disposal and preferences with respect to the construction material, environment, to understand any existing concern for the environment, social interactions, to see if there is external help from organizations and how relationships are inside the community, and socioeconomic, to understand the community.

\subsection{Application of the Approach in Rural Localities of Chiapas}

Located in the state of Chiapas in the southern part of Mexico, Pijijiapan is home to 50,079 inhabitants distributed in 788 rural communities with a high marginalization index (0.51). About $71.1 \%$ of the population is poor $(21.7 \%$ of whom live in extreme poverty), and there is only one urban municipality [47-49]. The geographic location of the study area, displayed in Figure 1, is divided into three main regions: Coast, mountain, and plain. The location of the communities surveyed is also indicated. The total sample size was $180,80 \%$ of which corresponded to the users interviewed, while $20 \%$ corresponded to the decision-makers (community leaders, officials, or health workers). A total of 156 valid interviews were obtained after the elimination of responses that were incomplete or contained inconsistent answers. 
Table 1. Indicators and variables established to evaluate user preferences on sanitation systems.

\begin{tabular}{|c|c|c|}
\hline \multicolumn{3}{|c|}{ User Preferences } \\
\hline Indicator & Variables & References \\
\hline Cost & $\begin{array}{ll}\text { - } & \text { Consumables } \\
\text { - } & \text { Cleaning } \\
\text { - } & \text { Investment }\end{array}$ & {$[8,35-39]$} \\
\hline Esthetics & $\begin{array}{ll}\text { - } & \text { Type of floor } \\
\text { - } & \text { Color } \\
\text { - } & \text { Space availability }\end{array}$ & {$[8,35,40]$} \\
\hline Ease & $\begin{array}{l}\text { - } \quad \text { Periodicity of maintenance } \\
\text { - } \quad \text { Frequency of daily use }\end{array}$ & {$[8,13,17,35]$} \\
\hline Hygiene & $\begin{array}{ll}\text { - } & \text { Periodicity of cleaning } \\
\text { - } & \text { Periodicity of hand washing }\end{array}$ & {$[8,35,40,41]$} \\
\hline Peer Influence & $\begin{array}{ll}\text { - } & \text { Customs } \\
\text { - } & \text { Will to change }\end{array}$ & {$[6,8,38]$} \\
\hline Surroundings & - Climatic conditions & {$[8,17,35,40,41]$} \\
\hline User & $\begin{array}{ll}\text { - } & \text { Privacy (shared community system } \\
& \text { or private system per house) } \\
\text { - } & \text { Daily use } \\
\text { - } & \text { Products } \\
\text { - } & \text { Water tap } \\
\text { - } & \text { Location (Inside, outside) } \\
\text { - } & \text { Hand washer } \\
\text { Ownership }\end{array}$ & {$[6,8,10,13,17,38,40-42]$} \\
\hline Technical & $\begin{array}{ll}\text { - } & \text { Toilet material } \\
\text { - } & \text { Wastes manipulation } \\
\text { - } & \text { Construction material } \\
\text { Proper disposal }\end{array}$ & {$[6,8,13,37,39,40,42-45]$} \\
\hline Environment & - Environmental health & [43-46] \\
\hline Social Interactions & $\begin{array}{ll}\text { - } & \text { External agent } \\
- & \text { Leadership } \\
\text { - } & \text { Community responsibility }\end{array}$ & {$[37,39,41,46]$} \\
\hline Socioeconomic & 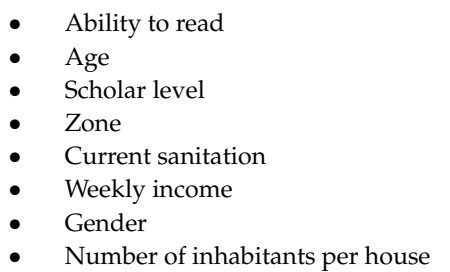 & $\begin{array}{l}\text { This indicator was added to understand the actual } \\
\text { situation of the area of study. The literature made an } \\
\text { indirect study on this indicator, but the present } \\
\text { authors viewed this as the most relevant indicator to } \\
\text { understand how a community functions. }\end{array}$ \\
\hline
\end{tabular}

\subsubsection{Socioeconomic Context}

The needs, experiences, and preferences of the users can be understood by placing them under a general context and by determining which sanitation systems are currently used. The majority of the respondents in the study area utilized unimproved and limited sanitation facilities. A large proportion of $84.4 \%$ of the respondents stated that they had flush toilets connected to septic tanks, making up the main sanitation system, $6.2 \%$ of the respondents stated that their flush toilets are connected to sewerage, $4.2 \%$ reported having no facility and using open defecation, and $3.1 \%$ said they had flush toilets connected to a sanitation system (see Table 2). The respondents showed apparent discomfort 
with the actual system, citing bad odor, flooding, and flying mosquitoes during the rainy season as the primary reasons.

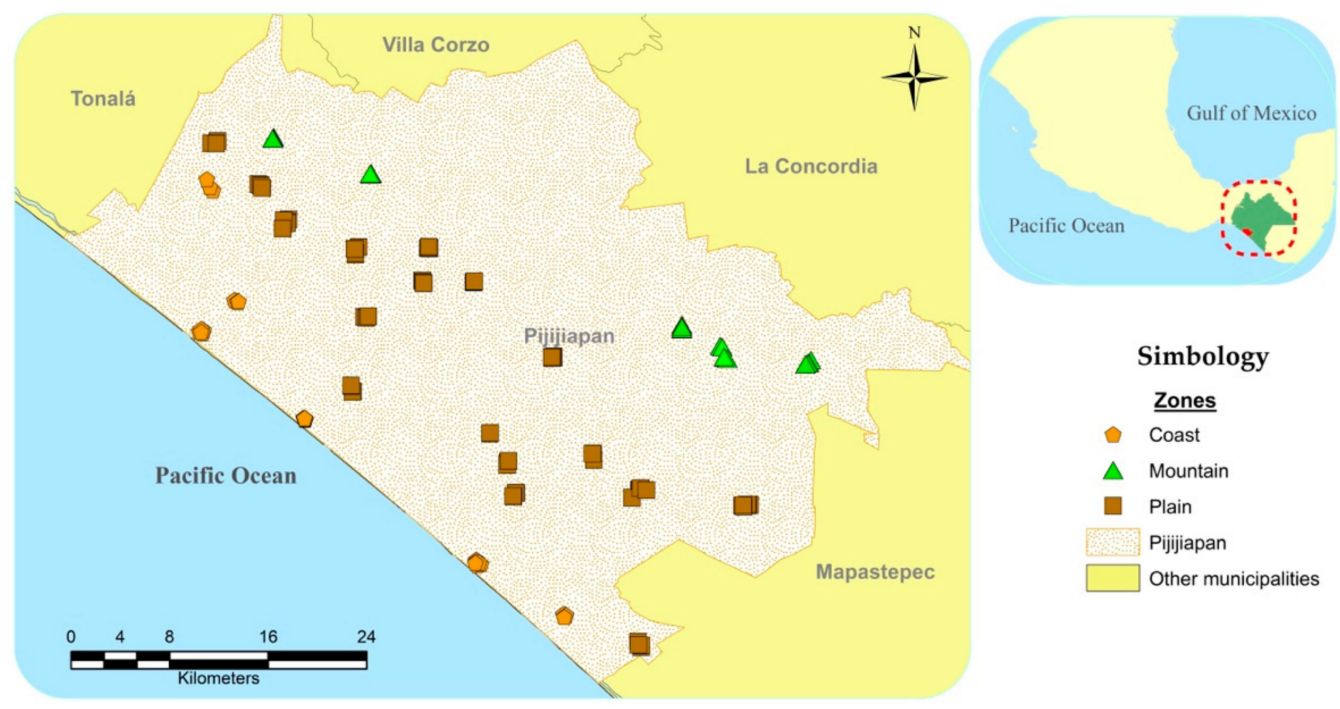

Figure 1. Area of study.

Table 2. Sanitation facilities in the area of study.

\begin{tabular}{ccc}
\hline Facility & Percentage & Number of Persons \\
\hline Flush toilet connected to septic tank & $84.4 \%$ & 109 \\
Flush toilet connected to the sewerage & $6.2 \%$ & 8 \\
Other (open defecation or do not have a facility) & $4.6 \%$ & 6 \\
Flush toilet connected to a sanitation system (stabilization ponds) & $3.1 \%$ & 4 \\
\hline
\end{tabular}

In terms of the importance of sanitation as a basic service, $67 \%$ of all the respondents indicated that sanitation is more important than piped or potable water, electricity, sewerage, mobile phone, internet, and television. Their preference seems to be highly influenced by different socioeconomic aspects. For instance, those who achieved higher education levels prioritized the service. Similarly, people with low incomes, those not fully able to read, old people, and small families preferred sanitation. In cases where sanitation was not regarded as important, electricity and potable or piped water services were the preference. Some users quoted, "If we have no electricity, then we cannot pump water," as their main water source was water wells.

The willingness of the users to change or improve the existing systems is likewise important. Thus, their willingness to change customs was part of the indicators assessed for new systems possible for implementation. Only 30\% of respondents indicated their extreme willingness on this aspect, $51 \%$ were disposed, whereas $19 \%$ were either indisposed or were no interested at all. People living in the mountain had more willingness than people living in the plains. People with septic tanks were the most interested in improving their systems as they prefer individual systems per home and thus, were willing to manage their waste. A good number of people also showed genuine interest in improving their sanitation system, although they lacked the financial resources. In a few cases, land tenure was an important factor as users did not show any disposition toward building sanitation infrastructure if they do not own the land. As one user stated, "Why would I invest in building in a place that is not mine?"

Under the same premise, the importance of sanitation against other services was analyzed and compared between the users and decision-makers to identify if authorities are aware of the local needs.

The users' and stakeholders' responses were similar, as shown in Table 3. Here, sanitation was perceived as generally a less important matter, mainly because the service is partially covered. Television, internet, and mobile phone services in these areas are usually not available yet. 
Table 3. Sanitation compared to other services.

\begin{tabular}{cccc}
\hline & Users & Decision-Makers & Services \\
\hline & $53 \%$ & $54 \%$ & Tubed water \\
Sanitation & $45 \%$ & $37 \%$ & Electricity \\
& $57 \%$ & $60 \%$ & Sewerage \\
& $72 \%$ & $77 \%$ & Mobile phone \\
& $82 \%$ & $86 \%$ & Internet \\
& $89 \%$ & $100 \%$ & Television \\
\hline
\end{tabular}

It should also be noted that trust was lacking between the community members and decision-makers. As a user quoted, "Community leaders support just their relatives or people they are closely related to." This aside, the leaders seemed to be aware of the needs and preferences of the communities.

\subsubsection{Relationships between the Variables and Indicators}

Aspects related to technical features, cost, ease of the system, and those directly linked to socioeconomic aspects were found to be the most important, whereas aspects associated with the surroundings, environment, hygiene, esthetics, peer influence, and social interactions were less relevant. A summary of the relationships between the variables and indicators that influence user preferences is displayed in Table 4.

\section{- Technical indicator}

Some variables of this indicator were related to variables of socioeconomic, ease cost, peer influence, and esthetics indicators. In terms of toilet material, older people, small families, and people living on the plains and coasts preferred porcelain. In these areas, the main productive activities were livestock, agriculture, and tourism. Thus, such activities could be drivers that influence people to prefer a common and known material. Other materials, such as cement, plastic, or iron, were preferred by young people and those living in the mountains. In all cases, porcelain was the only material they knew for toilets. However, a few expressed their willingness to try something different if necessary. Most people commonly asked for a better service, and the material was not a requisite concern. In the plains and coasts, people were willing to pay more than USD 20 for consumables and cleaning activities, and to invest in the system, whereas in the mountains, people were willing to pay less than that. Meanwhile, for waste management, men were willing to manage their waste, whereas women were not. People willing to manage their waste were also willing to do maintenance every week and to change their customs mainly for cleanliness, to prevent the existence of harmful pests, and to improve their quality of life. People who were not willing to do maintenance were also not willing to manage their waste. Finally, there were no important relationships between the variable construction material and proper disposal.

\section{- User indicator}

As mentioned above, the opinion of the users is vital in the implementation of the system proposed herein. Their preferences arise from satisfying their family's personal needs in the first place. Thus, the user indicator considered here is related to socioeconomic, ease, and esthetics indicators, whereas variables as daily use and products are related to the periodicity of maintenance and space availability, respectively. People would like to enjoy extra benefits, that is, in the form of marketable products, from managing their waste, while people who use a sanitation system at least three times daily have a specific physical space to build a sanitation system. In contrast, people who did not provide specific dimensions for the system to be built use it only once or twice a day. For the variable location, people who preferred a system outside the house were those receiving "Prospera" federal support, or those 
living in the mountains, whereas people who preferred a shared system were those willing to do maintenance at least twice a week and those who also preferred the system to be built in yellow or green. People without "Prospera" support preferred a private system, were willing to do maintenance once a week, every two weeks, or once a month, and preferred faint colors like blue, beige, and white if inside the house. Some people use phones while using the sanitation system and thus prefer the system in a location with the best signal reception, which is naturally poor in areas such as the mountains. Some people affirmed that the system is cleaner inside than outside the house, and some female users expressed that "white color allows us to see mosquitoes or undesirable fauna." In the case of ownership, people (men) were willing to change their customs. People with septic tanks and those who would like to have extra benefits from managing their waste preferred a sanitation system per home. Meanwhile, women preferred a system per community as they believe that having a system per home means that they have to perform all the cleaning activities. Lastly, variables such as a water tap, a hand-washer, and electricity were considered irrelevant.

\section{- Cost, ease, and esthetics}

The relationships between cost, ease, and esthetics indicators were insignificant, although some interesting issues were observed. For the cost, people willing to pay up to USD 250 for the installation of a new sanitation system receive less income than those who were willing to pay between USD 500 and 1500. People who attended higher school were willing to invest in a new sanitation system and to pay more than USD 3.0 for consumables. Conversely, people who were educated at the elementary level were not willing to invest and could not pay more than USD 3.0 for consumables. Education seemed to be an important factor for people willing to have better incomes and quality of life.

In terms of investment, people with higher incomes already have a better system than those who earn less money. Poorer people were willing to invest in sanitation. However, even if the cost appears to be irrelevant, their economic situation can represent a significant challenge. People might be willing to pay but saving money or collecting it can be difficult. In terms of the variables ease and esthetics, people living in houses with more members were willing to conduct more maintenance activities (at least twice a week) than people in houses with fewer members. People able to (fully) read preferred a cemented floor, whereas people who can read to some extent preferred a tiled floor. Depending on the zone, mostly on the plains and coasts, people wanted nice and beautiful systems. In terms of the esthetics indicator, no relationships were observed for color and space availability variables.

- Hygiene, peer influence, surroundings, environment, and social interactions

People with septic tanks were willing to change their customs and wanted security against rains, floods, wind, earthquakes, and pests. Furthermore, they preferred involvement in waste management to protect their health, nature, and productive activities, rather than to prevent water, soil, and air pollution. People did not show interest or awareness of the environmental impacts, probably because they were not fully informed regarding the negative implications of having low-quality sanitation services on health and hygiene.

\subsubsection{User Preferences}

Table 5 shows a list of the user preferences identified, based on the analysis of the relationships of the variables and indicators described above. Of the 11 indicators and 36 variables designed to assess user preferences, only eight variables of five indicators were relevant. 
Table 4. Matrix of indicators' relationships.

\begin{tabular}{|c|c|c|c|c|c|c|c|c|c|c|c|c|c|c|}
\hline \multirow[b]{2}{*}{ Indicators } & \multirow[b]{2}{*}{ Variables } & \multicolumn{9}{|c|}{ Socioeconomic } & \multicolumn{2}{|c|}{ Ease } & \multicolumn{2}{|r|}{ Cost } \\
\hline & & $\begin{array}{l}\text { Ability } \\
\text { to Read }\end{array}$ & Age & $\begin{array}{c}\text { Scholar } \\
\text { Level }\end{array}$ & $\begin{array}{l}\text { Government } \\
\text { Support }\end{array}$ & Zone & $\begin{array}{c}\text { Current } \\
\text { Sanitation }\end{array}$ & $\begin{array}{l}\text { Weekly } \\
\text { Income }\end{array}$ & Gender & $\begin{array}{l}\text { Number of } \\
\text { Inhabitants } \\
\text { Per House }\end{array}$ & $\begin{array}{l}\text { Periodicity of } \\
\text { Maintenance }\end{array}$ & $\begin{array}{l}\text { Frequency } \\
\text { of Daily } \\
\text { Use }\end{array}$ & Consumables & Cleaning Investment \\
\hline Technical & $\begin{array}{l}\text { Toilet material } \\
\text { Waste } \\
\text { manipulation } \\
\text { Construction } \\
\text { material } \\
\text { Proper disposal }\end{array}$ & & & & & & & & & & & & & \\
\hline User & $\begin{array}{l}\text { Daily use } \\
\text { Products } \\
\text { Water tap } \\
\text { Location } \\
\text { Hand-washer } \\
\text { Ownership } \\
\end{array}$ & & & & & & & & & & & & & \\
\hline Ease & $\begin{array}{l}\text { Periodicity of } \\
\text { maintenance } \\
\text { Frequency of } \\
\text { daily use }\end{array}$ & & & & & & & & & & & & & \\
\hline Cost & $\begin{array}{l}\text { Consumables } \\
\text { Cleaning } \\
\text { Investment }\end{array}$ & & & & & & & & & & & & & \\
\hline
\end{tabular}


Table 5. User preferences on sanitation systems.

\begin{tabular}{|c|c|c|c|c|}
\hline Indicator & Preference & Description & Percentage & Number of Persons \\
\hline \multirow{2}{*}{ User } & $\begin{array}{l}\text { - Private sanitation systems } \\
\text { per house }\end{array}$ & To avoid community conflicts & $75.2 \%$ & 91 \\
\hline & $\begin{array}{l}\text { - Marketable products } \\
\text { as manure }\end{array}$ & To have extra income & $63.6 \%$ & 77 \\
\hline \multirow{4}{*}{ Esthetics } & $\begin{array}{l}\text { - The system outside } \\
\text { the house }\end{array}$ & To keep it far from the house & $48.7 \%$ & 59 \\
\hline & $\begin{array}{l}\text { Faint colors like white, } \\
\text { beige, light blue, } \\
\text { and yellow }\end{array}$ & To detect harmful fauna & $38.8 \%$ & 47 \\
\hline & $\begin{array}{l}\text { - Dark colors like green } \\
\text { and blue }\end{array}$ & No specific reasons given & $29.7 \%$ & 36 \\
\hline & - Cement or tile floor & To facilitate cleaning activities & $76 \%$ & 92 \\
\hline Cost & $\begin{array}{l}\text { - Low construction and } \\
\text { maintenance costs }\end{array}$ & $\begin{array}{l}\text { To be able to afford and } \\
\text { maintain the system }\end{array}$ & $52.8 \%$ & 64 \\
\hline Technical & - $\quad$ Porcelain toilet & $\begin{array}{l}\text { To have the most known and } \\
\text { common material }\end{array}$ & $63.6 \%$ & 77 \\
\hline Surroundings & $\begin{array}{l}\text { - Protection against climatic } \\
\text { conditions and health risks }\end{array}$ & $\begin{array}{l}\text { To avoid rains, floods, wind, } \\
\text { earthquakes, and pests }\end{array}$ & $82.6 \%$ & 100 \\
\hline
\end{tabular}




\section{Discussion}

The SDGs on sanitation has pinpointed the current need for developing ecological and conventional sanitation technologies in close collaboration with the users [13]. Thus, new holistic approaches have been and are being designed to evaluate users' preferences on sanitation systems to ensure their success. Unfortunately, only a handful of researchers have undertaken the task of analyzing and understanding user preferences, so the task remains large. In addition, most of the current approaches focus on one or two aspects of sanitation, such as usage or ownership, and cost or technical features [8], whereas some have a significant number of variables [6]. Moreover, researchers such as Simiyu [18] and Conradin [50] have evaluated technologies where they were already implemented, and as Nawab et al. [13] suggested, it is possible and probably better to conduct the evaluation before the design and implementation based on user preferences, to improve and maybe ensure the acceptance of such systems. Until now, initiatives to address the lack of basic sanitation worldwide have ignored the human aspect, and the approaches do not represent what users need or prefer in a sanitation system [12]. This study incorporated the analysis of user preferences as part of the design, planning, and implementation process of a sanitation system to achieve universal basic sanitation coverage. Therefore, user preferences, along with the technical components that make a sanitation system efficient, can lead to ensuring the correct performance and appropriation of sanitation technologies $[8,51]$.

In this study as well, localities were found to have less access to improved sanitation services and poorer associated behaviors. Their current sanitation system keeps nutrients out of the agroecological cycle, which may contribute to significant environmental impacts [13]. The system also provides a breeding ground for harmful fauna such as mosquitoes, diffusion of bad odor, and groundwater contamination, which are health risk factors for the possible transmission of contagious and serious illnesses such as malaria, Zika, chikungunya, and dengue [52,53]. When a sanitation system has an impact on health (sanitary risks, transmission of diseases, and malnutrition), environment (water pollution and groundwater over-extraction), well-being (safety, dignity, and gender equality), and the economy (cost of health and environmental degradation) of communities, it consequently affects the capacity of an area for sustainable development [52]. According to Imbach [54], "Sustainable development is the permanent process towards the satisfaction of all fundamental human needs without irreversible degradation of the environment." In this context, fundamental human needs are needs that must be satisfied to achieve a dignified life. These are related to the individual, the surroundings, and a productive life. People living in rural and poor populations need motivation to satisfy these needs, being usually more concerned about their daily sources of food, water, shelter, and security rather than sanitation [13].

Interestingly, in 2015, Mexico claimed that it has "achieved" its MDG sanitation target, with $85 \%$ of its population (urban and rural) having access to improved sanitation services (however, this figure was more pertinent to sewerage access and not specifically to sanitation) [21]. Comparing the official figures provided by CONAGUA (National Water Commission of Mexico) and the United Nations (Table 6), it is no doubt that Mexico has achieved $92.8 \%$ of national sewerage coverage. However, only $45.54 \%$ of the population has been using safely managed sanitation. Thus, the technical implementation (coverage) of the systems was not equal to the percentage of usage. As a matter of fact, in the specific case of rural areas, the national sewerage coverage was barely $77.5 \%$, while in Chiapas specifically, it was $68.9 \%$, with no data available on the proportion of people using a safely managed sanitation system. 
Table 6. CONAGUA official numbers on sanitation in Mexico.

\begin{tabular}{|c|c|c|c|c|c|c|}
\hline & Year & $\begin{array}{l}\text { Population with } \\
\text { Sewage to Public } \\
\text { Net or Septic } \\
\text { Tank (Million) }\end{array}$ & $\begin{array}{l}\text { Population } \\
\text { with } \\
\text { Sewage } \\
\text { (Million) }\end{array}$ & $\begin{array}{c}\text { Sewage Coverage } \\
\text { to Public Net or } \\
\text { Septic Tank (\%) }\end{array}$ & $\begin{array}{c}\text { Sewage } \\
\text { Coverage } \\
(\%)\end{array}$ & $\begin{array}{c}\text { People Using a } \\
\text { Safely Managed } \\
\text { Sanitation Service } \\
(\%)\end{array}$ \\
\hline \multirow{4}{*}{$\begin{array}{c}\text { General } \\
\text { national } \\
\text { level }\end{array}$} & 2000 & 69.5 & 72.7 & 72.8 & 76.2 & 17.72 \\
\hline & 2005 & 83.5 & 85.6 & 83.5 & 85.6 & 23.78 \\
\hline & 2010 & 96.9 & 99.1 & 87.7 & 89.6 & 34.13 \\
\hline & 2015 & 109.5 & 110.9 & 91.4 & 92.8 & 45.54 \\
\hline \multirow{4}{*}{$\begin{array}{c}\text { Rural } \\
\text { national } \\
\text { level }\end{array}$} & 2000 & 7.5 & 8.9 & 31 & 36.7 & - \\
\hline & 2005 & 12.8 & 13.8 & 53.3 & 57.5 & - \\
\hline & 2010 & 16.4 & 17.5 & 63.6 & 67.7 & - \\
\hline & 2015 & 2.4 & 21.3 & 74.2 & 77.5 & - \\
\hline \multirow{4}{*}{$\begin{array}{c}\text { General state } \\
\text { (Chiapas) } \\
\text { level }\end{array}$} & 2000 & - & - & - & - & - \\
\hline & 2005 & - & - & - & 74.7 & - \\
\hline & 2010 & - & 3.83 & - & $81 \%$ & - \\
\hline & 2015 & - & 4.4 & - & 84.4 & - \\
\hline \multirow{4}{*}{$\begin{array}{c}\text { Rural state } \\
\text { (Chiapas) } \\
\text { level }\end{array}$} & 2000 & - & 8.9 & - & 36.7 & - \\
\hline & 2005 & - & 13.8 & - & 57.5 & - \\
\hline & 2010 & - & 17.8 & - & 68.9 & - \\
\hline & 2015 & - & - & - & - & - \\
\hline \multicolumn{7}{|c|}{$\begin{array}{c}\text { - NO DATA } \\
\text { Sources: }[21,55,56]\end{array}$} \\
\hline
\end{tabular}

The findings describe that the situation in rural settlements remains far from being sustainable and dignifying. Thus, it is imperative to improve sanitation facilities and increase awareness regarding its importance in reducing health risks and poverty and supporting socioeconomic development [52]. With the urgency to achieve sustainable development through MDGs, implementers have prioritized the construction of sanitation systems over ensuring their use and user acceptance [3]. Moreover, faulty designs, inadequate technical knowledge, and unsuitable technologies $[51,57,58]$ are important aspects to consider to understand why systems fail to be adequate. Of equal importance are social values and cultural variations that influence the type of technology appropriate for a specific community context [57]. When understanding user needs, experiences, and preferences, it is important to comprehend what current choices are available and what treatment methods can be used [32].

The study results show very clearly that in rural areas where people are marginalized, there is a need for basic services with a technology adapted on a local basis, meeting payment for these services, and maintenance possibilities. It is also important to consider the user preferences associated with the structural and functional parts of the system, payment capacity associated with the implementation, use, and construction of the system, and protection users need from the environment that surrounds them. Cost is a crucial factor for the success and broad implementation of a system. For instance, a higher cost can influence the decision of the users to accept or refuse the implementation and use of a system $[50,59]$. Indeed, affordability is one of the most defiant constraints. If the technology is not affordable for the majority of potential users, then it is not suitable for the circumstances $[57,60]$.

In some cases, preferences such as the esthetics of a system could be an important issue. However, in poor rural areas where people are marginalized, the preference is commonly basic services. In these areas, the most important element is the sanitation service itself, where the appearance of the toilet or the system is not a must for the community to accept, as opposed to the assertion of [17] "where sanitation facilities are lacking or not functional, a pleasant-looking and functional toilet is a source of pride." Meanwhile, shared systems can be a source of community conflicts. For instance, when users do not maintain hygiene in the toilet vicinity, then unsanitary conditions may initiate failure on the appropriation of the system and subsequently lacerate community relationships and complicate the optimal management of the system, maintenance, repairs, waste management, profits, cleaning, etc. Depending on the social capital, in some cases, users would not want to avoid creating problems [61], which justifies why they would rather have private systems than shared. Furthermore, financial barriers can represent a significant challenge in terms of the willingness of users to pay. Although they want to pay, saving, or collecting money may be difficult for them. Another issue is the lack of trust 
between the community or family members when the utilization of money is involved [61]. In the area of study, the majority simply could not afford sanitation charges. Thus, the government is not able to settle fees to the service, first, because it has no financial and infrastructural capacity to give basic sanitation services and second, because of the lack of trust in monetary management [3]. As a result, improvements in sanitation are difficult to achieve in the area.

In another perspective, focusing only on user preferences is not completely accurate. In this study, people in the locale did not show any interest in and awareness of the environmental and health impacts of poor sanitation, presumably because they were not fully informed of the negative externalities and implications of the lack of quality sanitation services on health and hygiene. Lack of awareness of this aspect is often related to poor educational standards. Nevertheless, it has been shown that poor and illiterate people have the potential and capacity to make good choices if they are given the opportunity to be involved from the start to the conclusion of sanitation projects [13]. Awareness is crucial in introducing good interventions and communicating the importance of sanitation to ensure a healthy community [62]. In other words, being active in the development of sanitation projects or at least knowing a little more about sanitation can benefit the system and the knowledge of people as individuals and as a community.

Furthermore, the government plays an important role in achieving full coverage of sanitation services. In the past, it was not a priority, and there were deliberate actions that permanently disrupted a sanitation system's use, maintenance, and performance, thereby creating mistrust and expectations from people for free services from the government, even when they are not poor $[3,63]$. Likewise, direct user and stakeholder participation, as well as empowerment by intermediate-level organizations, can provide an avenue to identify the needs of the community [57,64]. This implies that current and future interventions in the design, selection, development, and monitoring of technologies and the subsequent provision of sanitation services should involve community decision-makers who understand people's culture and behavior, to develop strategies with users as part of the process and to implement feasible, affordable, and user-accepted sanitation systems $[6,7,9,14,15]$.

Finally, although the focus of the study was on rural communities in Mexico, this does not limit the application and analysis of sanitation in other countries having the same problems related to basic sanitation, as those observed in Table 7, with a low proportion of the population using safe sanitation services.

Table 7. United Nations official statistics on sanitation services in selected countries, 2015.

\begin{tabular}{cccc}
\hline \multicolumn{3}{c}{ Proportion of Population Using Safely Managed Sanitation Services in Different Countries in 2015 } \\
\hline Country & Percentage & Country & Percentage \\
\hline China, Hong Kong, and & & & \\
Macao Special & 100 & Ecuador & 74.36 \\
Administration Region & 99.02 & Colombia & 71.12 \\
United States of America & 98.18 & Bangladesh & 55.67 \\
Spain & 97.19 & Mexico & 42.61 \\
Japan & 99.22 & Congo & 37 \\
Germany & 93.31 & Pakistan & 35.64 \\
France & 75.51 & Nigeria & 19.4 \\
Russian Federation & \multicolumn{2}{c}{ Source: [56] } \\
\hline \multicolumn{2}{r}{}
\end{tabular}

\section{Conclusions}

A comprehensive approach was proposed to identify the variables and indicators that allow the integration of human issues (user preferences) in the selection and creation of more holistic sanitation strategies, technologies, systems, and services. The proposed approach was shown to be effective in the identification of user preferences and, therefore, is recommended to be an intrinsic part of the 
design, planning, and implementation process to lead rural communities to achieve sustainability and SDGs on universal basic sanitation.

As it was necessary to understand how culture, preferences, practices, and socioeconomic conditions directly affect the possibilities for users to gain access to basic sustainable sanitation services, the approach was assessed in the rural communities of Chiapas, the poorest state in Mexico. The results showed that sanitation is an important service for the users. Nevertheless, if there is a lack of other services, the concern toward sanitation could be affected by the priority to meet daily needs, such as food and shelter.

With regard to preferences linked to the system's technical features, its esthetics, costs, and socioeconomic-related aspects were the most important to be considered for the provision of basic sanitation. The most important preferences of the users were privacy and protection proportioned by the system, the type of material for the toilet and the floor, and the costs of construction and maintenance. These preferences need to be an intrinsic part of the design, planning, and implementation processes to lead rural communities toward sustainability and to achieve SDGs of universal basic sanitation coverage. These elements, along with awareness of sanitation and government support, could help increase the appropriation and success in the use and implementation of basic sanitation services, as well as help recognize the limitations of certain types of sanitation systems and technologies before they are implemented. It is practical to say that leading rural communities to be sustainable remains a long and arduous task, but sanitation is not an isolated topic, as cultural, political, and economic forces are driving it, which means that it must be within a holistic framework that takes into account all the resources available in the community. The priority should be to design basic sanitation services based on user preferences.

Author Contributions: Investigation, T.T.-C. and J.A.G.-R.; writing-original draft, T.T.-C. and J.A.G.-R.; review and editing, M.Á.L.Z. and R.E.P.-G.; formal analysis, R.E.P.-G. and T.T.-C.; data curation, R.E.P.-G. and T.T.-C.; funding acquisition, M.Á.L.Z. All authors have read and agreed to the published version of the manuscript.

Funding: This research was supported by the National Council of Science and Technology of Mexico (CONACYT) and the Tecnologico de Monterrey.

Acknowledgments: We would like to acknowledge all the people surveyed to gather the information presented herein. Without them, this article would not have been possible. We also thank the National Council of Science and Technology of Mexico (CONACYT) and the Tecnologico de Monterrey for supporting this research.

Conflicts of Interest: The authors declare no conflict of interest. The funders had no role in the design of the study; the collection, analyses, or interpretation of data; the writing of the manuscript or the decision to publish the results.

\section{References}

1. Franceys, R.; Pickford, J.; Reed, R. A Guide to Development of On-Site Sanitation; WHO: Geneva, Switzerland, 1992.

2. WHO. Progress on Sanitation and Drinking Water: Update and MDG Assessment 2015; World Health Organization: Geneva, Switzerland, 2015.

3. Turrén-Cruz, T.; García-Rodríguez, J.; López Zavala, M. Evaluation of Sanitation Strategies and Initiatives Implemented in Mexico from Community Capitals Point of View. Water 2019, 11, 295. [CrossRef]

4. UN. We Can End Poverty: Millenium Development Goals and Beyond. 2015. Available online: https: //www.un.org/millenniumgoals/bkgd.shtml (accessed on 11 April 2019).

5. Paterson, C.; Mara, D.; Curtis, T. Pro-poor sanitation technologies. Geoforum 2007, 38, 901-907. [CrossRef]

6. Sinha, A.; Nagel, C.; Schmidt, W.; Torondel, B.; Boisson, S. Assessing patterns and determinants of latrine use in rural settings: A longitudinal study in Odisha, India. Int. J. Hyg. Environ. Health 2017, 220, 906-915. [CrossRef] [PubMed]

7. UNDP. Target 6: Clean water and sanitation. In Sustainable Development Goals; United Nations Development Programme: New York, NY, USA, 2018.

8. Seymour, Z.; Hughes, J. Sanitation in developing countries: A systematic review of user preferences and motivations. J. Water Sanit. Hyg. Dev. 2014, 4, 681-691. [CrossRef] 
9. EAWAG. Household-Centred Environmental Sanitation Implementing the Bellagio Principles in Urban Environmental Sanitation Provisional Guideline for Decision-Makers; Swiss Federal of Aquatic Science: Duebendorf, Switzerland, June 2005.

10. Sherpa, M.G.; Lüthi, C.; Koottatep, T. Applying the Household-Centered Environmental Sanitation planning approach: A case study from Nepal. J. Water Sanit. Hyg. Dev. 2012, 2, 124-132. [CrossRef]

11. Méndez-Fajardo, S.; Opazo, M.; Romero-Picón, Y.; Pérez-Muzuzu, B.-C. Metodología para la apropiación de tecnologías de saneamiento básico en comunidades indígenas. Cuad. Desarro. Rural 2011, 8, 153-176.

12. Jiménez, A.; Cortobius, M.; Kjellén, M. Water, sanitation and hygiene and indigenous peoples: A review of the literature. Water Int. 2014, 39, 277-293. [CrossRef]

13. Nawab, B.; Nyborg, I.L.P.; Esser, K.B.; Jenssen, P.D. Cultural preferences in designing ecological sanitation systems in North West Frontier Province, Pakistan. J. Environ. Psychol. 2006, 26, 236-246. [CrossRef]

14. Douglas, M.; Wildavsky, A. Risk and Culture An Essay on the Selection of Technological and Environmental Dangers; Univ. of California Press: Berkeley, CA, USA, 2010; ISBN 978-0-520-90739-3.

15. Jenkins, M.W.; Curtis, V. Achieving the 'good life': Why some people want latrines in rural Benin. Soc. Sci. Med. 2005, 61, 2446-2459. [CrossRef]

16. O'Keefe, M.; Lüthi, C.; Tumwebaze, I.K.; Tobias, R. Opportunities and limits to market-driven sanitation services: Evidence from urban informal settlements in East Africa. Environ. Urban. 2015, 27, 421-440. [CrossRef]

17. Simiyu, S. Preference for and characteristics of an appropriate sanitation technology for the slums of Kisumu, Kenya. Int. J. Urban Sustain. Dev. 2017, 9, 300-312. [CrossRef]

18. Tilley, E.; Strande, L.; Lüthi, C.; Mosler, H.-J.; Udert, K.M.; Gebauer, H.; Hering, J.G. Looking beyond Technology: An Integrated Approach to Water, Sanitation and Hygiene in Low Income Countries. Environ. Sci. Technol. 2014, 48, 9965-9970. [CrossRef] [PubMed]

19. Jiménez, N. El agua como derecho. Andamios 2018, 15, 327-330. [CrossRef]

20. Gutiérrez, R. El derecho fundamental al agua en México; un instrumento de protección para las personas y ecosistemas. Cuest. Const. Rev. Mex. Derecho Const. 2008, 18, 71-90. [CrossRef]

21. CONAGUA. Estadísticas del Agua en México; Comisión Nacional del Agua: Mexico City, Mexico, 2018.

22. OHCHR. UN Expert Calls on Mexico to Urgently Expand and Improve Water and Sanitation Provision for All; Office of the United Nations Human Rights Office of the High Commissioner: Mexico City, Mexico, 2017.

23. OXFAM. Promoviendo el Acceso Equitativo al Agua en México; OXFAM: Mexico City, Mexico, 2018.

24. Gutierrez-Jimenez, J. Evaluation of A Point-Of Use Water Purification System (Llaveoz) in a Rural Setting of Chiapas, Mexico. J. Microbiol. Exp. 2014, 1, 00015. [CrossRef]

25. Stevens, G.; Dias, R.H.; Thomas, K.J.A.; Rivera, J.A.; Carvalho, N.; Barquera, S.; Hill, K.; Ezzati, M. Characterizing the Epidemiological Transition in Mexico: National and Subnational Burden of Diseases, Injuries, and Risk Factors. PLoS Med. 2008, 5, e125.

26. CONEVAL. Medición de la Pobreza en México y en las Entidades Federativas 2016; National Council for the Evaluation of Social Development Policy: Mexico City, Mexico, 2016.

27. Hausmann, R.; Cheston, T.; Santos, M. The Economic Complexity of Chiapas: Existing Capabilities and Possibilities for Productive Diversification; Center for International Development at Harvard University: Cambridge, MA, USA, 2015.

28. Consejo Consultivo del Agua A.C. El Agua en Chiapas; Consejo Consultivo del Agua, A.C.: Mexico City, Mexico, 2015.

29. Sustainable Development Goals Fund. Water and Sanitation Management with a Gender Perspective in Mexico; Sustainable Development Goals Fund, Case Studies: Mexico City, Mexico, 2017.

30. Instituto del Agua de Chiapas. Problemática Principal del Agua; Gobierno del Estado de Chiapas: Chiapas, Mexico, 2018.

31. Samsom, E. Geopolitical Ecology of Rebellion on Environmental Quality in Northeast Chiapas, Mexico; Texas State University: San Marcos, TX, USA, 2011.

32. Program for Appropriate Technology in Health, PATH. Africa User Research in Water E Sanitation, Ethiopia; PATH: Seattle, WA, USA, 2013.

33. Spiegel, M.R.; Stephens, L.J. Estadística; McGraw-Hill: Mexico City, Mexico, 2009; ISBN 978-970-10-6887-8. 
34. National Science Foundation (NSF). Interpreting the Common Rule for the Protection of Human Subjects for Behavioral and Social Science Research-Snow Ball Sampling; National Science Foundation: Alexandria, VA, USA, 2019.

35. Molinos-Senante, M.; Gómez, T.; Garrido-Baserba, M.; Caballero, R.; Sala-Garrido, R. Assessing the sustainability of small wastewater treatment systems: A composite indicator approach. Sci. Total Environ. 2014, 497, 607-617. [CrossRef]

36. Lucich, I.; Gonzalez, K.; Malky, A. Preferencias y Disposición a Pagar de Los Usuarios del Servicio de Abastecimiento de Agua Potable en la Ciudad de Tarapoto; Programa de Investigaciones Económicas Aplicadas para la Conservación en la Amazonía Andina, de la Unidad de Apoyo de ICAA y Conservación Estratégica: Lima, Peru, 2015.

37. Ministry of Economy and Finance of Peru; Agencia de Cooperación Internacional del Japón. Pautas de Orientación Sectorial para la Evaluación Ex Post de Proyectos de Inversión Pública Sector Saneamiento; Agencia de Cooperación Internacional del Japón y Ministerio de Economía y Finanzas del Perú: Lima, Peru, 2012.

38. World Bank. Evaluación del Impacto Económico del Saneamiento en Bolivia 2015; World Bank Group: Washington, DC, USA, 2015.

39. Rojas, F.; Horst, M.; Heiland, S.; Venegas, P. Hacia Modelos de Gestión Sostenibles en Agua Potable y Saneamiento; Biblioteca Virtual de la Cooperación Alemana: La Paz, Bolivia, 2005.

40. Ness, S. Evaluation of School VIP Latrines and User Preferences and Motivations for Adopting Communal Sanitation Technologies in Zwedru, Liberia. Master's Thesis, University of South Florida, Tampa, FL, USA, 2015.

41. Alcalá, A.; Gurrutxaga, M. Análisis de preferencias del paisaje urbano entre barrios compactos y barrios postindustriales en Vitoria-Gasteiz. Implicaciones en la planificación urbana. An. Geogr. Univ. Complut. 2016, 36, 11. [CrossRef]

42. Smits, S.; Tamayo, S.; Ibarra, V.; Rojas, J.; Benavidez, A.; Bey, V. Gobernanza y Sostenibilidad de los Sistemas de Agua Potable y Saneamiento Rurales en Colombia; Inter-American Development Bank: Washington, DC, USA, 2012.

43. Yale University Center for Environmental Law \& Policy; Center for International Earth Science Information Network of Columbia University; World Economic Forum. 2018 Environmental Performance Index; Yale University Center for Environmental Law \& Policy: New Haven, CT, USA, 2018.

44. Oxford Economic Research Associates. Barnes Quality of Service Regulation; Oxford Economic Research Associates: Oxford, UK, 1995; ISBN 978-1-873482-07-0.

45. Ferro, G. Indicadores de Eficiencia en Agua y Saneamiento a Partir de Costos Medios e Indicadores de Productividad Parcial; Centro de Estudios Económicos de la Regulación: Buenos Aires, Argentina, 1999; ISBN 987-519-044-6.

46. Ministry of Environment and Water of Bolivia Enfoque Sectorial. Enfoque Sectorial Amplio para Agua y Saneamiento en Áreas Rurales con Población Menor a 2.000 Habitantes; Ministry of Environment and Water of Bolivia: La Paz, Bolivia, 2011.

47. CONAPO. Índice de Marginación por Municipio 1990-2015; Consejo Nacional de Población: Mexico City, Mexico, 2016.

48. CONEVAL. Pobreza a Nivel Municipio 2015; National Council for the Evaluation of Social Development Policy: Mexico City, Mexico, 2015.

49. Secretaría de Desarrollo Social, SEDESOL. Catálogo de Localidades: Sistema de Apoyo para la Planeación del PDZP; SEDESOL: Mexico City, Mexico, 2010.

50. Conradin, K. Ecological Sanitation in the Khuvsgul Area, Northern Mongolia: Socio-Cultural Parameters and Acceptance. Master's Thesis, University of Basel Institute of Geography, Basel, Switzerland, 2007.

51. Kaminsky, J.; Javernick-Will, A. Causes for Sustainable Maintenance and Operation of On-Site Sanitation Systems. In Proceedings of the Construction Research Congress 2012, West Lafayette, IN, USA, 21-23 May 2012; American Society of Civil Engineers: West Lafayette, IN, USA, 2012; pp. 2270-2279.

52. Hutton, G.; Chase, C. The Knowledge Base for Achieving the Sustainable Development Goal Targets on Water Supply, Sanitation and Hygiene. Int. J. Environ. Res. Public Health 2016, 13, 536. [CrossRef]

53. Vásquez, W.F.; Alicea-Planas, J. Unbundling household preferences for improved sanitation: A choice experiment from an urban settlement in Nicaragua. J. Environ. Manag. 2018, 218, 477-485. [CrossRef]

54. Imbach, C.A. Analizando las Conexiones Entre la Satisfacción de las Necesidades Fundamentales y los Recursos de las Comunidades Rurales, 1st ed.; Geolatina Ediciones: Turrialba, Costa Rica, 2016. 
55. CONAGUA. Situación del Subsector Agua Potable y Alcantarillado, 2011 ed.; Comisión Nacional del Agua: Mexico City, Mexico, 2011.

56. United Nations. Proportion of Population Using Safely Managed Drinking Water Services (Percent); United Nations Global SDG Dashboard; United Nations: New York, NY, USA, 2019.

57. Murphy, H.M.; McBean, E.A.; Farahbakhsh, K. Appropriate technology-A comprehensive approach for water and sanitation in the developing world. Technol. Soc. 2009, 31, 158-167. [CrossRef]

58. Sujaritpong, S.; Nitivattananon, V. Factors influencing wastewater management performance: Case study of housing estates in suburban Bangkok, Thailand. J. Environ. Manag. 2009, 90, 455-465. [CrossRef] [PubMed]

59. Cronin, A.A.; Ohikata, M.; Kumar, M. Social and economic cost-benefit analysis of sanitation in Odisha State, India. J. Water Sanit. Hyg. Dev. 2014, 4, 521-531. [CrossRef]

60. Mwirigi, J.; Balana, B.B.; Mugisha, J.; Walekhwa, P.; Melamu, R.; Nakami, S.; Makenzi, P. Socio-economic hurdles to widespread adoption of small-scale biogas digesters in Sub-Saharan Africa: A review. Biomass Bioenergy 2014, 70, 17-25. [CrossRef]

61. Shiras, T.; Cumming, O.; Brown, J.; Muneme, B.; Nala, R.; Dreibelbis, R. Shared Sanitation Management and the Role of Social Capital: Findings from an Urban Sanitation Intervention in Maputo, Mozambique. Int. J. Environ. Res. Public Health 2018, 15, 2222. [CrossRef] [PubMed]

62. Alagidede, P.; Alagidede, A.N. The public health effects of water and sanitation in selected West African countries. Public Health 2016, 130, 59-63. [CrossRef]

63. Davis, A.; Javernick-Will, A.; Cook, S.M. The use of qualitative comparative analysis to identify pathways to successful and failed sanitation systems. Sci. Total Environ. 2019, 663, 507-517. [CrossRef]

64. Katukiza, A.Y.; Ronteltap, M.; Oleja, A.; Niwagaba, C.B.; Kansiime, F.; Lens, P.N.L. Selection of sustainable sanitation technologies for urban slums-A case of Bwaise III in Kampala, Uganda. Sci. Total Environ. 2010, 409, 52-62. [CrossRef]

(C) 2020 by the authors. Licensee MDPI, Basel, Switzerland. This article is an open access article distributed under the terms and conditions of the Creative Commons Attribution (CC BY) license (http://creativecommons.org/licenses/by/4.0/). 